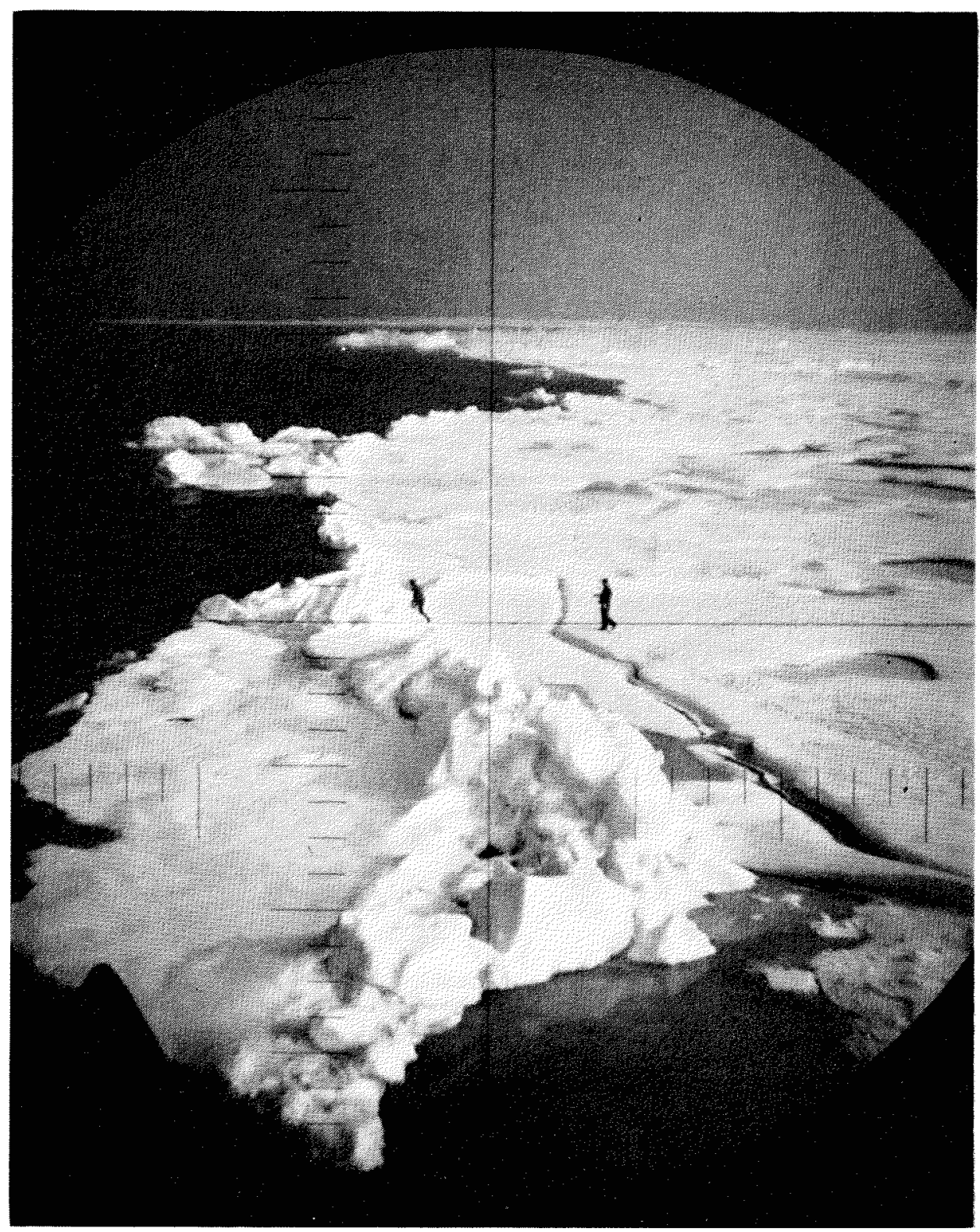

U.S. Navy Photo

Periscope view of crew members of USS Seadragon on the ice during the polar cruise $\mathbf{1 9 6 0 .}$ 


\title{
Commentary
}

\section{ARCTIC SCIENCE AND THE NUCLEAR SUBMARINE}

\author{
Arthur E. Molloy*
}

$\mathbf{T}$ HE early arctic research carried out by land-based groups was limited by many factors. Severe weather conditions had to be endured for long periods of time, and reliance placed on a logistics base that was of a semi-permanent nature. In addition the transport of men, material, and equipment were problems that required personnel occupied primarily with support and logistics. Research was confined mainly to coastal regions and the study of broad ocean areas was neglected, but the need for research in the ocean areas was always evident.

Investigations of the Arctic Ocean are now being conducted by both the United States and the Soviet Union by using research stations on drifting ice floes. This type of station has proved to be moderately successful, although they have disadvantages. First among these is the inherent danger of the ice floes breaking up sooner or later. Second, the ice in the Arctic Ocean follows a reasonably well-defined and generally predictable path, which limits the area that can be covered. Third, the ice-floe stations require logistic support by shore-based personnel. In addition, there are housekeeping duties that call for extra personnel as otherwise a heavy burden is placed on the scientific staff at the station. To meet these conditions the U.S. Navy and U.S. Air Force have had to furnish both ground-based facilities and drift-station personnel to support and maintain their respective arctic research programs. Another problem is that of transportation to and from a remote base. Seasonal changes and adverse weather conditions limit the periods when station personnel can be brought in and out (Calvert 1960). A final problem germane to this type of station concerns efficiency. The conduct of co-ordinated scientific research in an efficient manner requires that all these difficulties are surmounted and that quarters and facilities are provided that meet at least minimum living standards.

* U.S. Navy Hydrographic Office, Washington, D.C. 
It has been proved that drifting stations are definitely suited for specific scientific studies. An improvement on this type of station has been suggested. A specially constructed ship, frozen in the ice at a pre-selected place, would follow the now reasonably well-known drift pattern. This would be more than a return to the idea conceived and successfully carried out by Nansen and his party many years ago. With today's improvements in equipment, instruments, and communications, backed by the experience accumulated over many years, the modern arctic scientist would not suffer many of the hardships endured by the early arctic explorers. The suggested improvement should receive serious consideration, as it may prove in the long run to be both more economical and certainly more efficient than the present drifting ice-floe station.

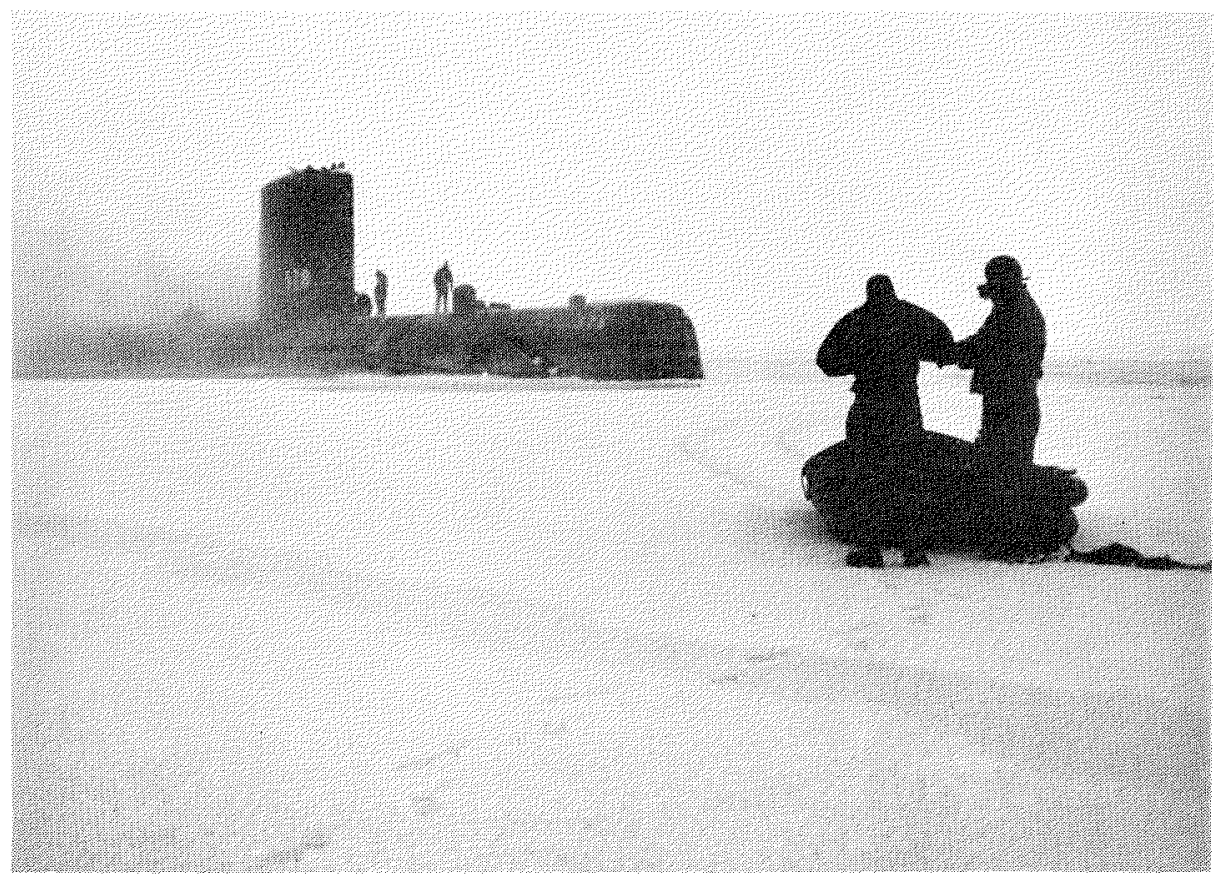

U.S. Navy Photo

When the U.S. Navy submarine USS Skate surfaced during her polar voyage in March 1959, survey parties used a rubber raft for exploring the pack ice.

The entire Arctic Ocean has now ceased to be remote and is open to study on a year-round basis by nuclear submarines (Strong 1961). Admittedly, there are limitations to the use of a nuclear submarine for arctic research, but the advantages heavily out-weigh the disadvantages. 
First among the advantages to be gained through the use of this type of vehicle is mobility (Lyon and Boyle 1962). The nuclear submarine is a self-contained community capable of operating under all arctic conditions for extended periods of time. Its mobility is not a function of pre-determined drift patterns, for the submarine can be directed to any desired place, at a wide range of speed and depth. With its special equipment, such as underwater television and SONAR, it can "see" and "hear" below the surface (Steele 1962). There is adequate space for modest laboratory facilities, a controlled atmosphere, and accommodation for a scientific staff, who are comfortable and have every incentive for conducting research (Molloy 1961).

Another advantage, and an equally important one, is the natural protection that the arctic environment offers to the submarine. The polar ice pack that presents such serious obstacles to the conduct of oceanographic research from the surface can be used to advantage by the nuclear submarine. It provides a nearly homogeneous environment free from disturbances of weather and other factors that the oceanographer encounters in the open ocean.

The advantages of submarine research in the Arctic are even more readily apparent after evaluating the accomplishments of the U.S. Navy's arctic submarine cruises during the past few years. The floor of the Arctic Ocean was sounded continuously during each cruise (Lyon and Boyle 1962). As a result of this, there is now more information available on the bathymetry of the Arctic Ocean than had been obtained during the previous 75 years of arctic exploration. We have now more data relating to the ice pack over broad areas and under various seasonal conditions than ever before. Ice and water samples, as well as bathythermograph observations, also have been obtained at various points in the arctic basin (LaFond 1960).

In addition the submarine itself has been a prime research tool whose advantages have not been limited to being a vehicle for transportation (Lyon and Boyle 1962). For example, surfacings through the ice have answered some of the questions relating to the ice cover. In many respects the Arctic has been the laboratory and the submarine the instrument with which the research was carried out (Lyon 1961).

The arctic cruises of the U.S. Navy submarines have not been conducted as purely oceanographic ventures, but diversified scientific programs have been carried out during each of the cruises (Strong 1961). It is manifest from these modest beginnings that the nuclear submarine is an ideal platform from which to launch a research program of rather large dimensions.

What specific type of research program can we plan? To answer this question we must first recognize that there should exist a three-fold plan of investigation. Its major categories should be: surveys (systematic investigations) that map all parameters; basic research; and applied research. The nuclear submarine is at present the only means by which large-area, in-situ investigations of the Arctic Ocean can be carried out (LaFond 1960).

In conjunction with the surveys, certain problems relating to both basic and applied research can be approached. There are important fields of 
research that should be considered for incorporation into any realistic plan. The research plan should be flexible and should attempt to connect with research conducted from present conventional platforms. It should be farreaching and, at the same time, be co-ordinated with existing long-range national research plans. It should allow for participation by all interests, including private research institutions as well as government agencies.

Long-range planning should include the use of more than one nuclear submarine and provide for more than one or two cruises per year.

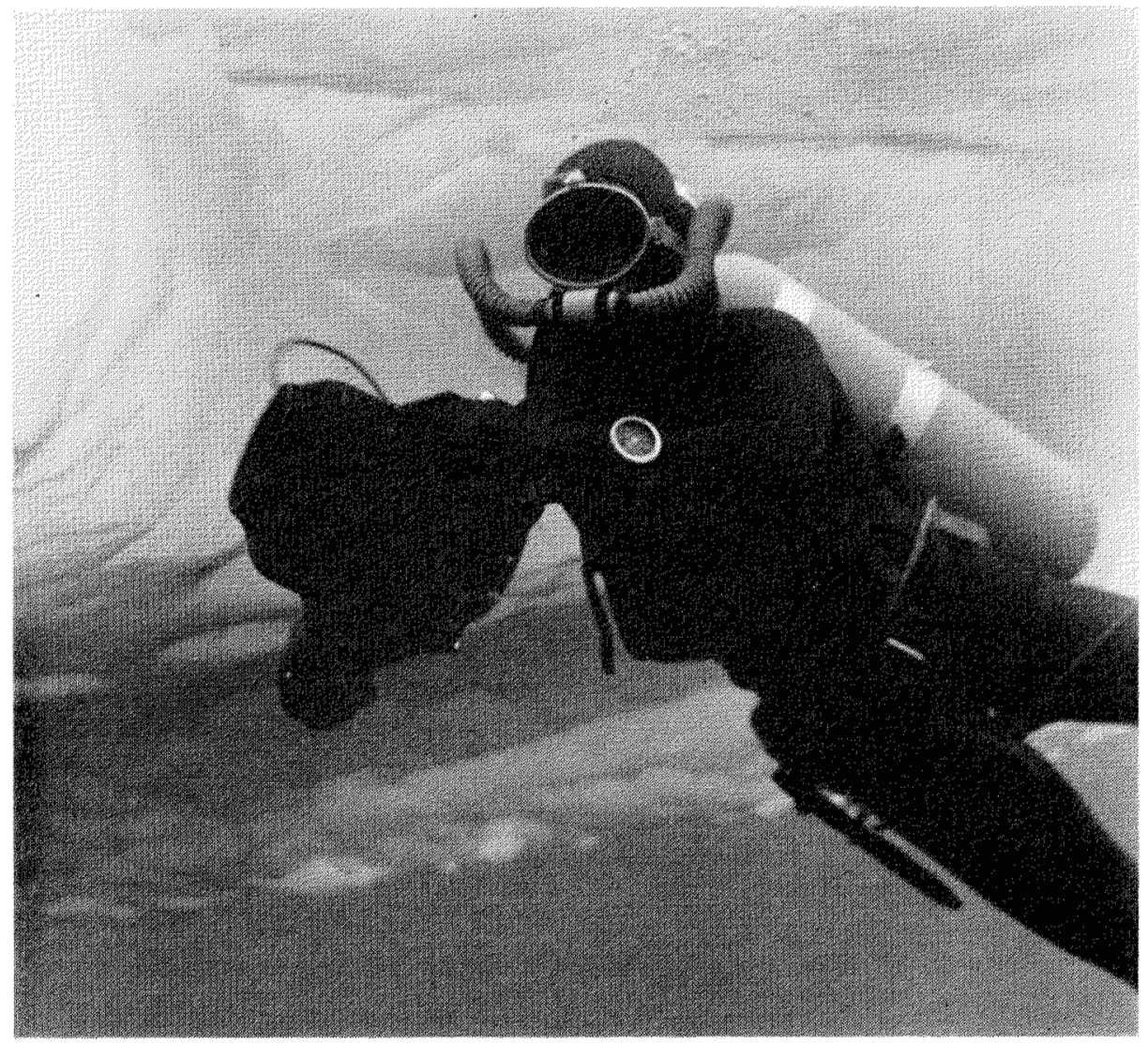

U.S. Navy Photo

Frogman Crowley, a member of the underwater photography team of USS Seadragon, swimming under the arctic ice while taking the first photographs of the underside of the ice at the North Pole.

The advantage to both basic and applied research is obvious. Routine collection of data can be made in part by the crew of the submarine. Training of a nominal length would be required, but this is no unsurmountable obstacle. The value obtained for miles steamed would be far in excess of that of present day arctic research making use of existing techniques. 
The thrust northward by the nations that ring the Arctic Ocean is only now getting under way, and the economic potential wealth of these vast areas is as yet in an early stage of development (Lyon and Boyle 1962). The nuclear submarine, equipped to perform a variety of scientific investigations in the field of oceanography, marine geology, geophysics, and meteorology, could begin immediately to expand the scope of arctic science, which, to date, has not been fully exploited. Suitable instruments and equipment are available, and development of new instrumentation to meet specific requirements can begin with the advent of a concerted arctic research effort.

A completely equipped nuclear submarine, operating independently of any shore-based establishment, and offering working conditions that can be provided by no other means in the Arctic at present, is certainly worthy of serious consideration.

I am greatly indebted to Dr. Waldo K. Lyon of the U.S. Navy Electronics Laboratory for guidance and critical review, and to Captain C. N. G. Hendrix, U.S. Navy, for recommendations and assistance in pointing out certain aspects of the use of a submarine for a research vessel.

The views expressed in this paper are those of the author and do not necessarily reflect those of the Department of the Navy.

\section{References}

Calvert, J. 1960. Surface at the Pole. New York: McGraw-Hill Book Co., Inc. 220 pp. LaFond, E. 1960. Arctic oceanography by submarine. U.N. Naval Inst. Proc. 691:90-6. Lyon, W. 1961. Ocean and sea research in the Arctic Ocean via submarine. Trans. N.Y. Acad. Sci., Ser. II, 23:662-74.

Lyon, W. and R. Boyle. 1962. The Arctic Ocean. Undersea Technol. 3:17-20.

Molloy, A. 1961. Exploratory bathymetric surveys in the Arctic Ocean. Surveying and Mapping. 21:451-7.

Steele, G. 1962. Seadragon; northwest under the ice. New York: E. P. Dutton and Co., Inc. $255 \mathrm{pp}$.

Strong, J. 1961. The opening of the Arctic Ocean. U.S. Naval Inst. Proc. 704:58-65. 